Research Article

\title{
Spatiotemporal Evolution Patterns and Driving Factors of Synergistic Development of Culture, Sports, and Tourism Industries: The Case Study of China
}

\author{
Ji Li, ${ }^{1}$ Jiangtao Xia, ${ }^{2}$ Yifan Zuo, ${ }^{1}$ Jiabao Cui, ${ }^{1}$ Qihang Qiu, ${ }^{3}$ Xuan Liu, ${ }^{1}$ and Hongfa Zeng $\mathbb{D}^{1}$ \\ ${ }^{1}$ Department of Physical Education, Shenzhen University, Shenzhen 518061, China \\ ${ }^{2}$ School of Leisure Sports and Management, Guangzhou Sport University, Guangzhou 510632, China \\ ${ }^{3}$ Faculty of Human Geography and Planning, Adam Mickiewicz University, Poznan 61-680, Poland
}

Correspondence should be addressed to Hongfa Zeng; zenghongfa@szu.edu.cn

Received 17 August 2021; Revised 19 October 2021; Accepted 12 November 2021; Published 26 November 2021

Academic Editor: Xunjie Gou

Copyright $\odot 2021 \mathrm{Ji} \mathrm{Li}$ et al. This is an open access article distributed under the Creative Commons Attribution License, which permits unrestricted use, distribution, and reproduction in any medium, provided the original work is properly cited.

Synergistic development of the culture, sports, and tourism industries is an emerging trend in China, providing new formats for industrial evolution and fresh momentum for industrial upgrading. Therefore, building a robust framework to evaluate the synergistic development is relevant to China's economic and social development. This study used a coupling coordination model to calculate the coupling coordination degree of the three industries, for 31 provinces in China from 2013 to 2017. Subsequently, it employed spatial autocorrelation techniques and GeoDetector to identify factors affecting the synergistic development from global and local perspectives before discussing the driving mechanisms. The results showed that (1) the synergistic development of the three industries was generally stable with a slight imbalance. (2) The development level varied across regions. The general spatial pattern was low in northeastern and western China, stable and average in the central region, and high in the eastern region. (3) The synergistic development has a prominent "proximity dependence" effect reflected by a notable spatial agglomeration feature and positive spatial autocorrelation trend and (4) twenty-one indicators of six driving factors (industrial pulling force, population supporting force, consumer purchasing power, transportation pushing force, resource attraction force, and economic driving force) affected the synergistic development.

\section{Introduction}

In recent years, pursuing synergistic development across industries has become an emerging global trend. Various industries have been reshaped or integrated for optimising industrial structures and business models. Owing to considerable social and technological progress and an increasingly well-educated population in China, the culture, sports, and tourism (CST) industries have developed rapidly. Blurring boundaries among the three industries highlights the need for innovation and integration in reforming industrial structures. The synergistic development of CST industries could also expand the scope of the broader tertiary sector with new business formats, models, and products. The Chinese central government explicitly required a more coordinated development of the CST industries, for example, building more sports culture brands and developing boutique sports tourism events and routes. Numerous local governments have proposed policies to promote the development of CST industries. These supportive measures cover multiple dimensions, such as land allocation, fiscal assistance, financing accessibility, tax and levy incentives, and brand building. As they could considerably promote the development of other industries with their long industrial chains, CST industries are a critical driver of the Chinese economy. Therefore, insights into enhancing the coordinated development of the three essential industries are relevant to China's economic and social development. Moreover, they could also inform other countries' efforts to optimise the spatial layout of their industries and promote the sustainable and moderate development of the three industries.

The synergistic development across industries requires further extension and interpenetration of industrial chains 
and networks, involving structural adjustment and upgrading of the industries. In turn, it has also become an important path for industrial upgrading; numerous studies have examined how the synergistic development has promoted industrial upgrading [1]. In recent years, scholars have investigated the synergistic development in different industries. For instance, using evolutionary game analysis, Pingkuo et al. [2] explored the energy transition problem in the power generation industry from the perspective of the synergistic development, which can be regarded as the game of interest balance of the thermal power and energy power generation enterprises. Qiu et al. [3] investigated whether the tourism industry can promote rural economy and explored the synergistic development problem between agriculture and tourism based on a corresponding index system and a coupling coordination model. The study demonstrated the integrated development of the agricultural and tourism industries. Considering the sustainable and coordinated development in the logistics industry and the manufacturing industry, Gong et al. [4] adopted a three-stage superefficiency slack-based model (SBM) to analyse the Yangtze River Economic Belt of China. The results indicated that the logistics industry is relatively lagging in promoting the development of the manufacturing industry, and the overall levels of coordination between the two industries were limited. Similar studies have investigated other industries. Nevertheless, most scholars focus on the synergistic development between the two industries; only a few have integrated three different industries into the same system to explore their interaction and coupling mechanisms. Moreover, most studies have focused on time-series evolution comparisons, when the driving factors of the synergistic development of the industry lack attention.

The synergistic development across CST industries is a dynamic process. Driven by numerous factors, businesses in the industries with common interests remove industrial barriers and interpenetrate, extend, or restructure industrial chains and networks, leading to new business formats that follow the multidimensional integration of technologies, businesses, and markets [5]. The literature on synergistic development across CST industries has mainly focused on three combinations. The first is the synergistic development between the sports and tourism industries: concepts and definitions, intrinsic characteristics, and developmental challenges and strategies. Liang defined the synergistic development between the sports and tourism industries in terms of economics, stressing that tourism services should be offered on the basis of sports resources [6]. To create a tourism-oriented regional development strategy, Fugao and Li proposed and defined all-for-one sports tourism. They also classified the development models into the dominant, subordinate, symmetric, and derivative types, depending on how relevant industries coexist [7]. Zuo et al. adopted the Wuli-Shili-Renli system approach, a holistic analytical process that considers the physical world, social interactions, and human factors, to analyse the spatial distribution pattern of China's sports tourism resources. By adopting a geographic detector probe model as an analysis method, they found that government support and guidance, market cultivation and development, and economic benefits are drivers behind the development of sports tourism [8].

The second is the synergistic development between the sports and culture industries: mainly classification and definition of the two industries, achieving the synergistic development, and related constraints or bottlenecks. Zhang argued that sports and culture are interdependent. The culture industry could provide a better platform for developing the sports industry, which, in turn, would positively promote its own development [9]. Deli et al. suggested that the synergistic development between the sports and culture industries is preferred for sports development. To achieve this, the sports industry should customise its development on the basis of local geographic environment and cultural resources [10]. The third is the synergistic development between the culture and tourism industries. Compared with the other two combinations, studies on the interaction and synergistic development between the two industries had started earlier, although these are generally qualitative and on the sustainable development of the two industries. Bachleitner and Zins discussed the growing demand for cultural tourism and its social context. They also warned that while using cultural tourism as a development tool in rural areas, policymakers must carefully consider that key attraction factors, such as cultural identity and authenticity, may be destroyed by tourism development [11]. In the field of cultural heritage tourism, Rudokas et al. adopted a costbenefit analysis of tourism statistics to investigate the costeffectiveness of public investments in cultural heritage conservation and their capabilities in attracting tourism businesses [12]. Lestari et al. regarded culture as capital and urged local stakeholders to evaluate the cultural tourism industry from a capitalist perspective using a case study [13].

In summary, the three combinations have been investigated extensively. Although some studies have addressed relevant indicators for the three industries, others have focused on the synergistic development across the three industries. However, further studies are still needed in several directions. (1) The dynamics and evolutionary characteristics of the synergistic development across the CST industries. As discussed, the relevant studies have primarily explored the combinations of any two of the three industries and offered only theories about synergistic development. Therefore, in practice, the dynamics of the synergistic development of CST industries and the spatial and temporal characteristics of the development need to be investigated first. (2) The driving factors for the synergistic development of the CST industries: the driving factors identified could predict the dynamics of the synergistic development, thereby informing measures to promote the synergistic development of the CST industries. The CST industries are naturally coupled in three dimensions. They are successive in time, overlapping and mutually enhancing in space, and push each other's growth. The strength of the coupling relationship of the CST industries can be measured by a coupling degree. A higher coupling degree implies more spillover effects from increased efficiency in leveraging resources from the other two industries, thus making it more competitive than when depending on the resources of a single industry. In contrast, 
a lower coupling degree implies more independence or less interrelated industrial factors and structures, leading to a weak synergy among the industries. Therefore, using the coupling coordination model, this study measured the coupling coordination degree of the CST industries of 31 provinces (including provincial-level municipalities and autonomous regions, but excluding Hong Kong, Macao, and Taiwan) in China from 2013 to 2017 and followed the research framework of "spatial pattern-spatial effect" to reveal the synergistic development trend and related spatiotemporal evolution patterns of the cultural, sports, and tourism industries. GeoDetector was used to explore the driving factors of the synergistic development quantitatively. This study provides a more reasonable explanation of the mechanisms behind the observed patterns and expands theoretical and empirical research of CST industries, thereby informing the measures to enhance their synergistic development.

\section{Materials and Methods}

\subsection{Methods}

2.1.1. Entropy Method. To measure the development level of CST industries comprehensively, the weight of each indicator needs to be determined appropriately to ensure the evaluation results are robust, objective, and accurate. The entropy weighting method used in the study is more objective than the analytic hierarchy process. It assigns a weight mainly on the basis of information contained in the indicator, regardless of data linearity. By avoiding the interference of subjective factors effectively, it is also more reliable [14]. Owing to data availability, China's data were used in this study to calculate the weight.

2.1.2. Coupling Coordination Model. The coupling degree model maps the systematic coupling degree of the CST industries, reflecting its strength among the three systems. It was calculated as follows. Variable $q_{i}$ denotes the order parameter of each system of CST industry, $q_{i j}$ represents the indicator $j$ of the order parameter $i$, and the value is $x_{i j}(i=1$, $2 ; j=1,2, \ldots, n) . \operatorname{Max}\left(x_{i j}\right)$ and $\min \left(x_{i j}\right)$ are, respectively, the maximum and minimum values of the corresponding indicator of the order parameter at the critical point of system stability [15]. The function $q_{i j}$ for the efficacy of the CST industries on systematic order is as follows:

$$
q_{i j}=\left\{\begin{array}{l}
\frac{x_{i j}-\min \left(x_{i j}\right)}{\max \left(x_{i j}\right)-\min \left(x_{i j}\right)}, \quad q_{i j} \text { is positive, } \\
\frac{\max \left(x_{i j}\right)-x_{i j}}{\max \left(x_{i j}\right)-\min \left(x_{i j}\right)}, \quad q_{i j} \text { is negative. }
\end{array}\right.
$$

For the three subsystems of CST industries, the contribution of each indicator to the entire system was calculated by a linear weighting method with the following formula:

$$
q_{i}=\sum_{j=1}^{n} \lambda_{i j} q_{i j}, \sum_{j=1}^{n} \lambda_{i j}=1,
$$

where $q_{i}$ is the comprehensive evaluation efficacy of the three subsystems of culture, sports, and tourism industries in year $j$ and $\lambda_{i j}$ denotes the weight determined by the entropy weighting method [16].

According to the coupling theory in physics and relevant study results $[17,18]$, the efficacy contribution of each order parameter is calculated for building the coupling degree model to describe the interaction of the three subsystems of culture $q_{1}$, sports $q_{2}$, and tourism $q_{3}$ industries as follows:

$$
C\left(q_{1}, q_{2}, q_{3}\right)=3\left[\frac{q_{1} q_{2} q_{3}}{q_{1}+q_{2}+q_{3}}\right]^{1 / 3},
$$

where the value of the coupling degree $C$ is in the range of $[0$, 1]. The $C$ value approaching 1 implies that the three subsystems are reaching orderly development and desirable resonance coupling. On the contrary, the value edging nearer to 0 suggests that the three subsystems are slipping into a disordered state with poor coupling. Well aware of the possibility of disparity between lower efficacy of the three subsystems and higher coupling degree, we decided to build the coupling coordination model of the CST industries as follows:

$$
\begin{aligned}
& D=\sqrt{C T}, \\
& T=\frac{1}{3} q_{1}+\frac{1}{3} q_{2}+\frac{1}{3} q_{3},
\end{aligned}
$$

where $D$ is the coupling coordination degree and $T$ is the comprehensive evaluation index. Given the three subsystems' importance to the coupling relationship and drawing upon the results of prior studies $[17,18]$, we allocated the weight of $1 / 3$ for each of the three subsystems. A higher coupling coordination degree implies a higher matching degree between them, indicating that the subsystems are more likely to develop in an orderly manner. Furthermore, referring to relevant studies, we graded the coupling and coupling coordination degree as shown in Table 1.

2.1.3. Spatial Autocorrelation. Spatial autocorrelation measures the correlation between a geographic attribute and its value of a location with those of neighbouring localities $[19,20]$. To test for spatial autocorrelation, we used Moran's I index as follows:

$$
I=\frac{\sum_{i=1}^{n} \sum_{j=1}^{n} \omega_{i j}\left(X_{i}-\bar{X}\right)\left(X_{j}-\bar{X}\right)}{S^{2} \sum_{i=1}^{n} \sum_{j=1}^{n} \omega_{i j}},
$$

where $\omega$ is the spatial weight between locations $i$ and $j ; n$ denotes the number of locations; $X_{i}$ is the observed value for location $i$, and $X_{j}$ is that for location $j$. The value range of Moran's $I$ is -1 to 1 . Moran's $I>0$ indicates a positive spatial correlation, whereas Moran's $I<0$ indicates a negative spatial correlation. Moran's $I=0$ indicates an independent random distribution [21]. 
TABle 1: Classification criteria and grades of coupling and coupling coordination degree.

\begin{tabular}{lccc}
\hline & Coupling degree $C$ & \multicolumn{2}{c}{ Coupling coordination degree $D$} \\
Interval & Coupling stages & Interval & Coordination stages \\
\hline \multirow{2}{*}{$0 \leq C<0.3$} & Low-level coupling & $0 \leq D<0.1$ & Extreme imbalance \\
& & $0.1 \leq D<0.2$ & Severe imbalance \\
$0.3 \leq C<0.5$ & Partly engaged & $0.2 \leq D<0.3$ & Moderate imbalance \\
& & $0.3 \leq D<0.4$ & Slight imbalance \\
$0.5 \leq C<0.6$ & Initial break-in stage & $0.4 \leq D<0.5$ & Bordering imbalance \\
& & $0.5 \leq D<0.6$ & Barely coordinated \\
$0.6 \leq C<0.8$ & Deep break-in stage & $0.6 \leq D<0.7$ & Slightly coordinated \\
\multirow{2}{*}{$0.8 \leq C \leq 1$} & & $0.7 \leq D<0.8$ & Moderately coordinated \\
& & $0.8 \leq D<0.9$ & Satisfactorily coordinated \\
& High-level coupling & $0.9 \leq D \leq 1$ & Excellently coordinated \\
\hline
\end{tabular}

2.1.4. GeoDetector. GeoDetector is used to analyse and detect spatial variation, and in particular, to measure the extent to which a factor can explain a variation in the result variable, thereby identifying the source of the variation [22]. It is described by the following equation:

$$
q=1-\frac{\sum_{h=1}^{L} N_{h} \sigma_{h}^{2}}{N \sigma^{2}}
$$

where $L$ is the variable stratification, namely classification or partition; $N_{h}$ and $N$ are the number of units in layer $h$ and the whole area, respectively; $\sigma_{h}^{2}$ and $\sigma^{2}$ are the variances of the result variable in layer $h$ and the whole area, respectively; and $q$ represents the influence of an antecedent variable on the result variable. With the value range of $[0,1], q$ closer to 1 indicates that the antecedent variable has higher explanatory power on the result variable; conversely, when it approaches 0 , the explanatory power is lower. In this study, GeoDetector was used to identify the key factors that affect the coupled and coordinated development of the CST industries.

2.2. System of Indicators. Coupling is a concept in physics, referring to a phenomenon where two or more systems or modes of motion interact to achieve mutual influence and then synchronisation [23]. By nature, CST industries are substantially coupled and correlated. Given the complex relationship between these three industries, coupling theories have been used to analyse the interactions between their subsystems. Furthermore, the coupling degree and the coupling coordination degree have been used to describe how the three subsystems are interrelated, how they affect each other, and how they develop in a coordinated way, thereby revealing the dynamics behind the systematic coupling among China's CST industries (see Figure 1).

The conceptual model provides the basis for composing an industrial development index for CST industries with a carefully designed indicator evaluation system. Indicators were selected by referring to prior studies [20, 24-26] and in compliance with principles such as robustness, representativeness, feasibility, reliability, and availability. The resultant indicators for the three industries were grouped into the categories of production factors and industrial economy (see Table 2). Compared with previous studies, more of the culture industry indicators selected for this study are related

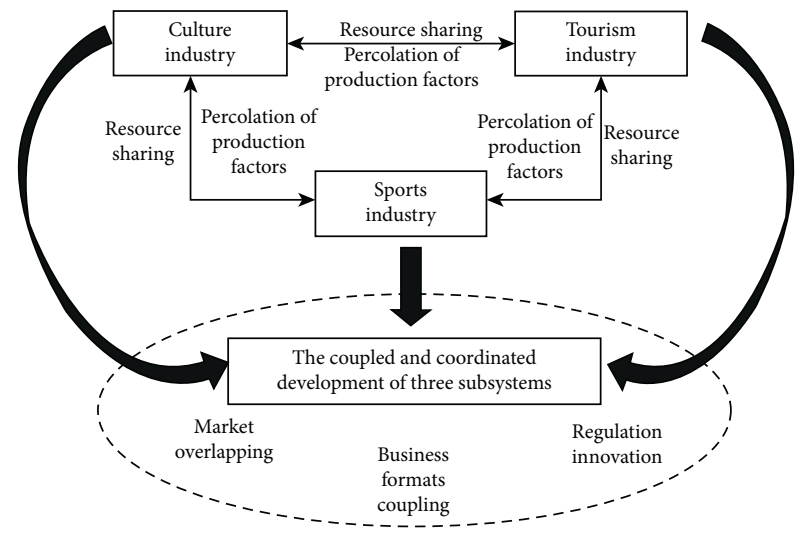

FIgUre 1: Conceptual model depicting the coupling mechanism of CST industries.

to cultural entertainment and recreational services that are ready to interact with sports and tourism industries. Therefore, the results shown later are inconsistent with those from previous studies [27].

2.3. Data Sources. Given the statistical definitions for indicators related to the CST industries, 2013-2017 data of 31 provinces in China (excluding Hong Kong, Macao, and Taiwan) were used in this study. The data were mainly from the China Statistical Yearbook, China Tourism Statistical Yearbook, and Annual Report of Mass Sports Development in China from 2013 to 2017. For some indicators, the data were supplemented by those from local statistical yearbooks, statistical communiques of local sports bureaus, and official websites of the Ministry of Finance of the People's Republic of China and China Marathon (https://www.runchina.org. $\mathrm{cn})$. Moreover, the map of China used in this study was taken from the Data Centre for Resources and Environmental Sciences of the Chinese Academy of Sciences (https://www. resdc.cn/Default.aspx).

\section{Results}

3.1. Overview of Coupling and Coordination among the Culture, Sports, and Tourism Industries. This study measured the coupling coordination degree of China's CST industries from 2013 to 2017. The results are shown in Table 3. In the 
TABLE 2: System of developmental indicators for the culture, sports, and tourism industries.

\begin{tabular}{|c|c|c|c|c|}
\hline Subsystems & Tier 1 indicators & Tier 2 indicators & Unit & Weight \\
\hline \multirow{7}{*}{$\begin{array}{l}\text { Culture } \\
\text { industry }\end{array}$} & \multirow{3}{*}{$\begin{array}{l}\text { Production } \\
\text { factors }\end{array}$} & Number of performing arts organisations & Number & 0.1544 \\
\hline & & Number of performing arts venues & Number & 0.1149 \\
\hline & & Number of performing arts performances & $\begin{array}{l}10,000 \\
\text { performances }\end{array}$ & 0.2388 \\
\hline & \multirow{4}{*}{$\begin{array}{l}\text { Industrial } \\
\text { economy }\end{array}$} & Attendance to domestic performances & 10,000 viewers & 0.2319 \\
\hline & & Number of visits to performing arts venues & 10,000 visits & 0.1802 \\
\hline & & $\begin{array}{l}\text { The consumer price index for culture and entertainment (last } \\
\text { year }=100)\end{array}$ & - & 0.0434 \\
\hline & & $\begin{array}{l}\text { The consumer price index for culture and entertainment products } \\
\text { (last year }=100)\end{array}$ & $\%$ & 0.0364 \\
\hline \multirow{6}{*}{ Sports industry } & \multirow{3}{*}{$\begin{array}{l}\text { Production } \\
\text { factors }\end{array}$} & Number of sports venues & Number & 0.1588 \\
\hline & & Sports lottery amount & 10,000 yuan & 0.1900 \\
\hline & & Number of marathon races & Number & 0.2006 \\
\hline & \multirow{3}{*}{$\begin{array}{l}\text { Industrial } \\
\text { economy }\end{array}$} & \multirow{3}{*}{$\begin{array}{c}\text { The consumer price index for sports products (last year }=100 \text { ) } \\
\text { The average salary of employed persons in urban sports organisations } \\
\text { organisations }\end{array}$} & $\%$ & 0.0696 \\
\hline & & & Yuan & 0.2302 \\
\hline & & & Yuan & 0.1508 \\
\hline \multirow{8}{*}{$\begin{array}{l}\text { Tourism } \\
\text { industry }\end{array}$} & \multirow{4}{*}{$\begin{array}{l}\text { Production } \\
\text { factors }\end{array}$} & Number of accommodation businesses & Number & 0.1414 \\
\hline & & Number of food and beverage businesses & Number & 0.1834 \\
\hline & & Total number of travel agencies & Number & 0.1192 \\
\hline & & Number of A-level tourist attractions & Number & 0.1240 \\
\hline & \multirow{4}{*}{$\begin{array}{l}\text { Industrial } \\
\text { economy }\end{array}$} & Passenger kilometres & 10,000 & 0.1253 \\
\hline & & Total tourism revenue & 10,000 yuan & 0.1180 \\
\hline & & Per capita tourism income & $\begin{array}{l}10,000 \text { yuan/ } \\
\text { person }\end{array}$ & 0.1086 \\
\hline & & Total tourism revenue as a percentage of GDP & $\%$ & 0.0802 \\
\hline
\end{tabular}

TABLE 3: Coupling and coordination of China's sports, tourism, and culture industries.

\begin{tabular}{cccccc}
\hline Year & $\begin{array}{c}C q_{1} \text { (culture } \\
\text { industry) }\end{array}$ & $\begin{array}{c}C q_{2} \text { (sports } \\
\text { industry) }\end{array}$ & $\begin{array}{c}C q_{3} \text { (tourism } \\
\text { industry) }\end{array}$ & $\begin{array}{c}D \text { (coupling coordination } \\
\text { degree) }\end{array}$ & $\begin{array}{c}\text { Industrial interaction } \\
\text { Coordination } \\
\text { grade }\end{array}$ \\
\hline 2013 & 0.2112 & 0.2661 & 0.3195 & 0.3568 & $\begin{array}{c}\text { Lagged culture and sports } \\
\text { industries }\end{array}$ \\
2014 & 0.2178 & 0.3197 & 0.3200 & 0.3707 & Lagged culture industry imbalance \\
2015 & 0.1928 & 0.2852 & 0.3264 & 0.3536 & Slight imbalance \\
2016 & 0.1811 & 0.3180 & 0.3231 & 0.3564 & Lagged culture industry Slight imbalance \\
2017 & 0.1983 & 0.3049 & 0.3165 & 0.3591 & Lagged culture industry Slight imbalance \\
\hline
\end{tabular}

2013-2017 period, the coupling coordination degree of China's CST industries generally changed little, fluctuating within a range of 0.3536 to 0.3707 . The comprehensive development level of the three industries was generally stable over the years with notable growth in the sports industry, a steady tourism industry, and a slightly declining culture industry. The coordination grade for CST industries had not changed notably in these five years. Persistent imbalance is not conducive to the synergistic development of the three industries, and thus, adjustment is urgently needed to optimise the industrial structure. In terms of the comprehensive development level, tourism industry $C q_{3}>$ sports industry $C q_{2}>$ culture industry $C q_{1}$. Moreover, the coordination and interaction can be characterised as lagged culture and sports industries in 2013 and a lagged culture industry after 2013. Before 2013, the tourism industry was far ahead of the sports and culture industries. After 2013, the gap between the sports and tourism industries narrowed significantly, especially in 2014 and 2016, to as low as 0.003 and 0.051 , respectively. The policies Several Opinions on Accelerating the Development of Sports Industry and Promoting Sports Consumption and National Fitness Plan (2016-2020) issued by the Chinese government in 2014 and 2016, respectively, can explain the developments as they might have motivated the sports industry's development. In contrast, compared with the sports and tourism industries, the consistently straggling culture industry encountered problems related to investments, ownership, technologies, and scale [25].

3.2. Characteristics of Spatiotemporal Evolution of the Coupling and Coordination among the Culture, Sports, and Tourism Industries. Using the coupling coordination degree model, this study measured the degree of the CST industries' coupling coordination in 31 provinces in China from 2013 to 2017, as shown in Figure 2. The changes in the grades of the provinces from 2013 to 2017 

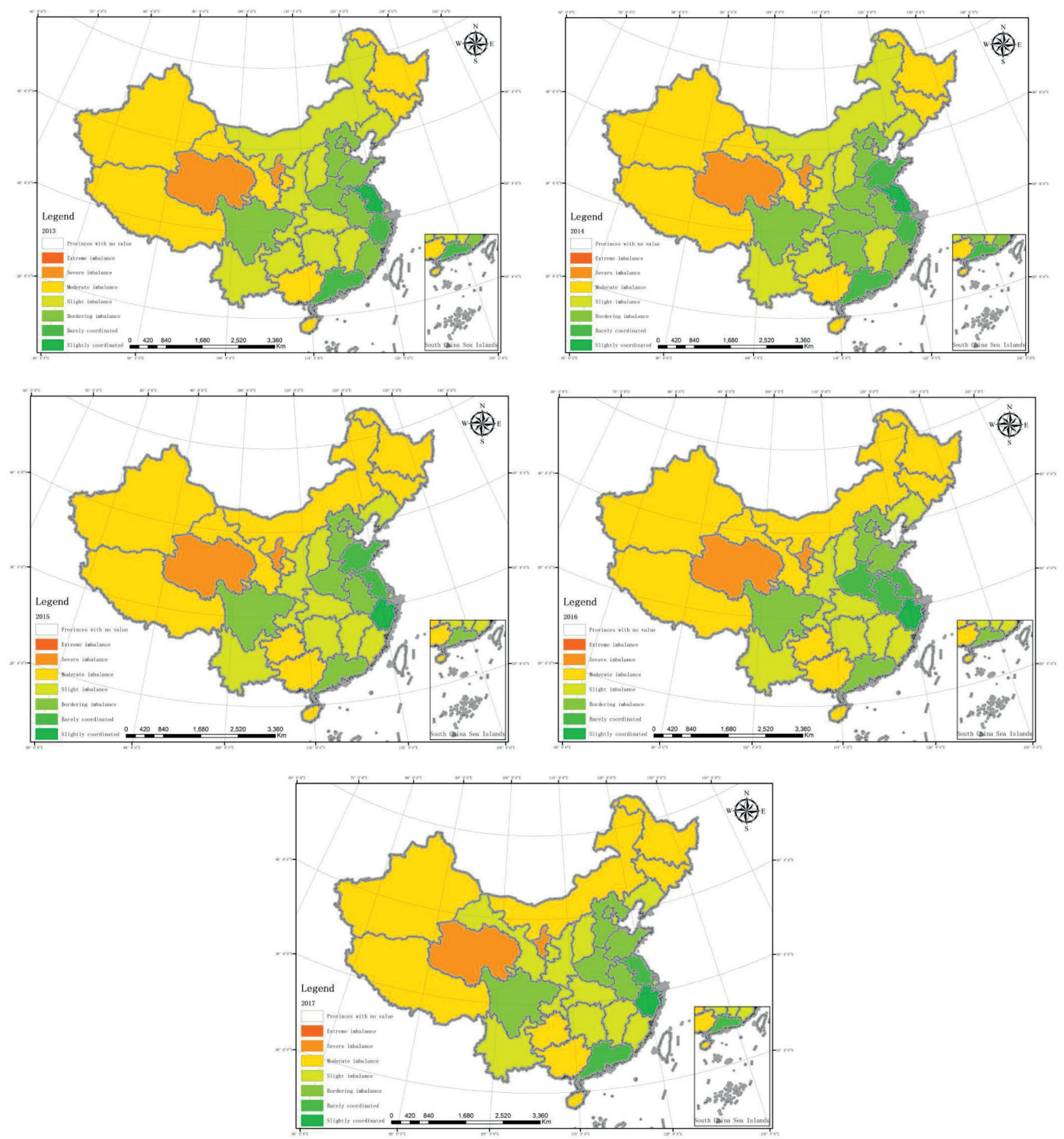

FIGURE 2: Coupling coordination grade of the CST industries in China's provinces from 2013 to 2017.

were minor and were distributed normally for the provinces. With the exception of a few provinces graded as severe imbalance and moderately coordinated, most were in the range of bordering imbalance to barely coordinated. Specifically, Inner Mongolia dropped from a state of bordering to moderate imbalance, and eastern China briefly upgraded from bordering imbalance to barely coordinated in 2016, before returning to the former grade the next year, whereas for the other provinces, the changes were minimal. Although the synergistic development across the CST industries has been widely debated, the lack of practical experience implies lagged effects of related economic policies.
Nevertheless, the coupling coordination degree in eastern China was much higher than the national average level with small but steady growth over the years. For example, in Zhejiang, Guangdong, Jiangsu, and Shandong, the degree increased moderately from 2013 to 2016 to the "coordinated" grade. Owing to stable growth, the degree was slightly higher than the national average in central China and was converging to the coordinated grade. In northeastern and western China, the degree improved too slowly to prevent imbalance, implying a considerable space for improvement.

This study employed the global spatial autocorrelation technique to explore the spatial characteristics and 
aggregation effects of the coupling coordination degree of the CST industries in China's provinces. ArcGIS 10.2 (Esri, Inc., Redlands, CA, USA) was used to calculate the global Moran's I index, which reflects the global autocorrelation of the coupling coordination degree, as shown in Table 4. The values of global Moran's I for the coupling coordination degree of CST industries from 2013 to 2017 were all positive with $Z(I)>3.5508$ and $P(I)<0.001$, indicating that the coupling coordination degree had a significant spatial aggregation potential. Over the years, global Moran's $I$ from 2013 to 2017 showed a wave-like movement. It was up from 2013 to 2014, down from 2014 to 2015, up from 2015 to 2016, and down again from 2016 to 2017, with a general upward trend. Notably, the peaks in 2014 and 2016 suggest that government policies had a positive role in increasing spatial autocorrelation. Moreover, the consistently positive values of $Z$ (I) from 2013 to 2017 indicate that the coupling coordination degree of China's CST industries had positive spatial autocorrelation. Given the spatial agglomeration and positive correlation, geographically neighbouring provinces had notable "proximity dependence" effects. More precisely, hot spots and cold spots are used to describe the distinctive spatial agglomeration forms.

The global spatial autocorrelation analysis revealed a general spatial agglomeration characteristic for the synergistic development of China's CST industries. To better analyse the evolution of local hot spots, based on the natural break classification in ArcGIS 10.2 (Esri, Inc., Redlands, CA, USA), we classified the provinces into the categories of cold spots, sub-cold spots, average spots, sub-hot spots, and hot spots. Figure 3 presents the results.

In general, the evolution of the spots can be characterised as follows. The number of hot spots, most in eastern China, increased moderately, particularly in inland areas. In the case of Anhui, surrounded by hot spots, the province was upgraded from a sub-hot spot to an emerging hot spot. The area of some cold spots decreased to a certain extent, notably in provinces along the national border and in western China. However, Tibet, Qinghai, Ningxia, and Heilongjiang remained consistent cold spots.

Moreover, the hot spots and sub-hot spots gradually expanded from eastern China to central and southwestern China, and from coastal provinces bordering the Yellow Sea and the East China Sea to those along the Yangtze River. Specifically, the hot spots in 2013 were Shandong, Jiangsu, Zhejiang, Henan, and Guangdong, whereas the sub-hot spots were Beijing, Hebei, Anhui, Hubei, Fujian, and Sichuan. In 2017, the hot spots were Anhui, Shandong, Jiangsu, Zhejiang, Henan, and Guangdong, and the sub-hot spots were Beijing, Shanghai, Chongqing, Hebei, Anhui, Hubei, Hunan, Fujian, and Sichuan. The results are encouraging signs of continuous, albeit moderate, improvement. In these spots, the synergistic development across CST industries was relatively satisfactory with mutual promoting effects among the provinces.

In contrast, the area of cold spots shrank, mostly in provinces along the border and in western China. More precisely, in 2013, the cold spots were Tibet, Qinghai, Ningxia, Heilongjiang, and Jilin, whereas the sub-cold spots were Tianjin, Inner Mongolia, Gansu, Xinjiang, Guizhou, Guangxi, and Hainan. By 2017, although the total number of cold and sub-cold spots did not change notably, the cold spots covered only Tibet, Qinghai, Ningxia, and Heilongjiang, whereas the sub-cold spots were Inner Mongolia, Gansu, Xinjiang, Guizhou, Guangxi, Hainan, and Jilin. How the synergistic development of CST industries in these provinces can be promoted by fully leveraging ethnic sports, culture, border trade, and border tourism along the border and in western China is a direction for future research. The key to the question may be the building of cultural, creative, and sports events, and exhibiting intellectual property (IP).

\subsection{Factors Driving the Coupling and Coordination among the} Culture, Sports, and Tourism Industries. As three complex systems, the CST industries are influenced by numerous factors during the synergistic development, such as their industrial development levels, population, transportation, resources, and the economy. In this study, GeoDetector was used to determine the influences of 21 indicators of six driving factors (industrial pulling force, population supporting force, consumer purchasing power, transportation pushing force, resource attraction force, and economic driving force) on the synergistic development of the CST industries. The previously obtained comprehensive development index of these industries was used to measure the industrial pulling force. The regional population supporting force was calculated using the data of the total population, the natural rate of growth, and employment. The number of people aged 15-64 years, per capita disposable income of residents, and per capita consumption expenditure of residents were used to measure the consumer purchasing power. Highway and railway mileage, public finance expenditure on transportation, and the total fixed asset investment (transportation, storage, and postal industry) were employed to gauge the transportation pushing force. To calculate the resource attraction force, the indicators were public finance expenditure on culture, sports, and media, business services, and others; and fixed asset investment in water conservation, environment, and the public facility management industry, and the catering and accommodation industry; and the culture, sports, and entertainment industry. We also used GDP per capita, tertiary sector GDP, and the latter as a percentage of total GDP to gauge the economic driving force.

The quick cluster analysis method in SPSS 24.0 (SPSS Inc., Chicago, IL, USA, 2019) was used to divide the driving factors of industrial pulling force, population supporting force, consumer purchasing power, transportation pushing force, resource attraction force, and economic driving force into five categories. Subsequently, the GeoDetector analysis program was used to calculate the effects of each driving factor on the synergistic development of the CST industries. The results are shown in Table 5 .

In Table 5, the value of $q$ reflects the extent to which the determining factor explains and affects the synergistic development of the CST industries. The higher the value of $q$, the higher the influence of the factor on the 
TABLE 4: Global autocorrelation analysis of coupling coordination degree of China's CST industries.

\begin{tabular}{lcccc}
\hline Year & Global Moran's $I$ & $Z(I)$ & $P(I)$ & Spatial distribution \\
\hline 2013 & 0.3968 & 3.5508 & 0.001 & Highly concentrated \\
2014 & 0.4469 & 3.9462 & 0.001 & Highly concentrated \\
2015 & 0.4278 & 3.7766 & 0.001 & Highly concentrated \\
2016 & 0.4546 & 4.0531 & 0.001 & Highly concentrated \\
2017 & 0.4346 & 3.8660 & 0.001 & Highly concentrated \\
\hline
\end{tabular}
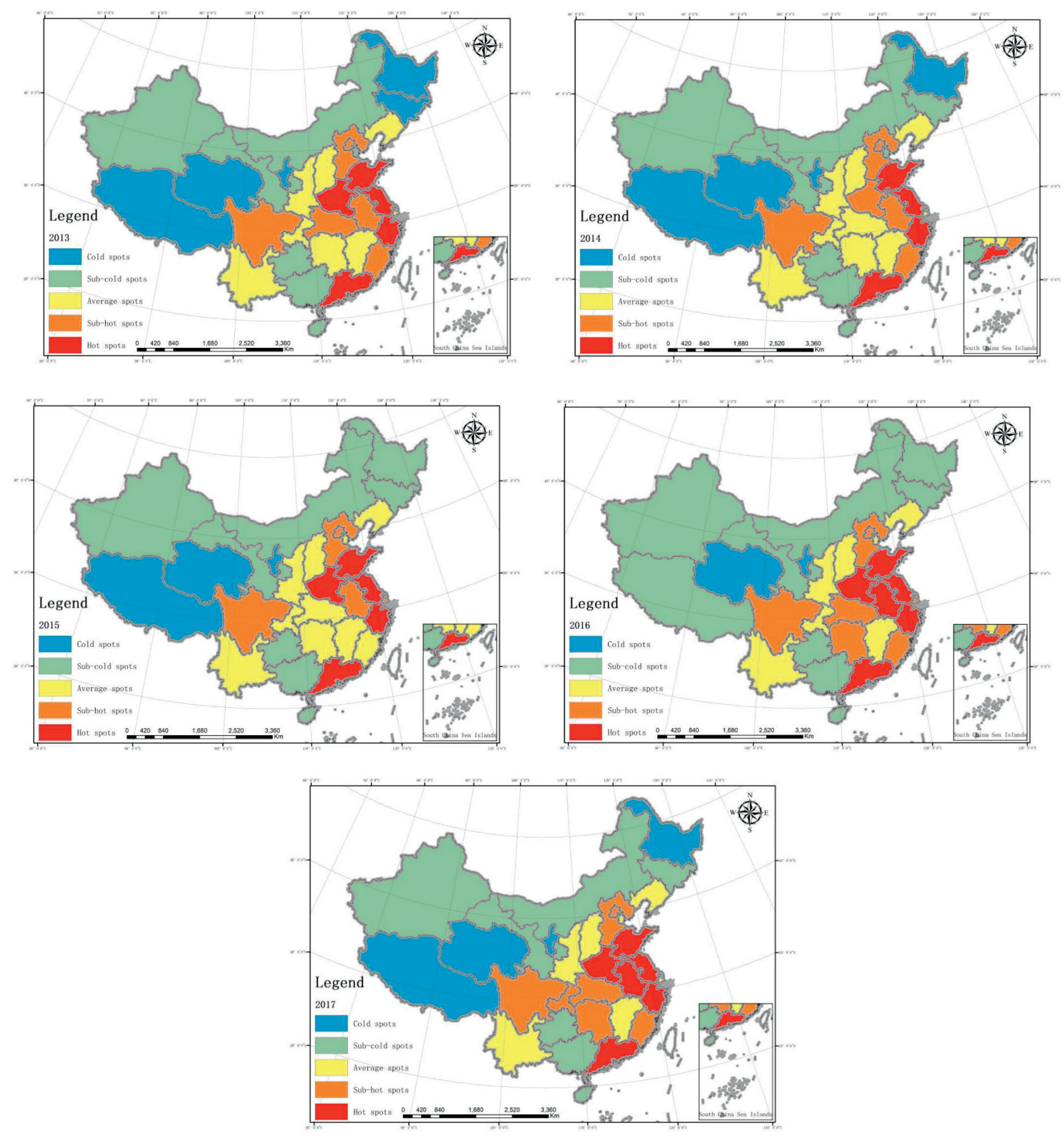

FIgURE 3: Cold to hot spots of synergistic development of CST industries in China's provinces from 2013 to 2017.

synergistic development. In contrast, when the value is lower, so is the impact. In general, among the six driving forces detected, the factors with the highest to lowest influence on the synergistic development of the CST industries were industrial pulling force (0.736>); resource attraction force $(0.551>)$; population supporting force $(0.540>)$; consumer purchasing power (0.395 > economic driving force $(0.380>))$; and 
TABLE 5: Driving factors affecting the synergistic development of CST industries ( $q$ value).

\begin{tabular}{|c|c|c|c|c|c|c|c|}
\hline Driving factors & Detecting indicators & 2013 & 2014 & 2015 & 2016 & 2017 & Mean \\
\hline \multirow{3}{*}{ Industrial pulling force } & Sports industry development & 0.639 & 0.648 & 0.621 & 0.669 & 0.637 & 0.643 \\
\hline & Tourism industry development & 0.792 & 0.766 & 0.836 & 0.840 & 0.815 & 0.810 \\
\hline & Culture industry development & 0.763 & 0.712 & 0.777 & 0.792 & 0.734 & 0.756 \\
\hline \multirow{3}{*}{$\begin{array}{l}\text { Population supporting } \\
\text { force }\end{array}$} & Total population (year-end) & 0.593 & 0.586 & 0.555 & 0.530 & 0.573 & 0.568 \\
\hline & Natural rate of growth & 0.494 & 0.184 & 0.394 & 0.168 & 0.153 & 0.278 \\
\hline & Employment & 0.822 & 0.771 & 0.787 & 0.751 & 0.735 & 0.773 \\
\hline \multirow{3}{*}{$\begin{array}{l}\text { Consumer purchasing } \\
\text { power }\end{array}$} & Number of people aged 15-64 years & 0.672 & 0.604 & 0.558 & 0.553 & 0.569 & 0.591 \\
\hline & Per capita disposable income of residents & 0.362 & 0.355 & 0.404 & 0.372 & 0.397 & 0.378 \\
\hline & Per capita consumption expenditure of residents & 0.234 & 0.191 & 0.218 & 0.220 & 0.221 & 0.217 \\
\hline \multirow{4}{*}{$\begin{array}{l}\text { Transportation pushing } \\
\text { force }\end{array}$} & Highway mileage & 0.131 & 0.120 & 0.102 & 0.115 & 0.131 & 0.120 \\
\hline & Railway mileage & 0.182 & 0.172 & 0.148 & 0.148 & 0.136 & 0.157 \\
\hline & Public finance expenditure (on transportation) & 0.474 & 0.417 & 0.500 & 0.606 & 0.422 & 0.484 \\
\hline & $\begin{array}{c}\text { Total fixed asset investment (transportation, storage, and postal } \\
\text { industry) }\end{array}$ & 0.628 & 0.546 & 0.647 & 0.443 & 0.479 & 0.549 \\
\hline \multirow{5}{*}{$\begin{array}{l}\text { Resource attraction } \\
\text { force }\end{array}$} & Public finance expenditure (on culture, sports, and media) & 0.657 & 0.670 & 0.695 & 0.502 & 0.471 & 0.599 \\
\hline & Public finance expenditure (on business services and others) & 0.791 & 0.685 & 0.742 & 0.578 & 0.585 & 0.676 \\
\hline & $\begin{array}{l}\text { Fixed asset investment (water conservation, environment, and public } \\
\text { facility management industry) }\end{array}$ & 0.524 & 0.523 & 0.432 & 0.418 & 0.479 & 0.475 \\
\hline & Fixed asset investment (catering and accommodation industry) & 0.525 & 0.427 & 0.516 & 0.392 & 0.447 & 0.461 \\
\hline & Fixed asset investment (culture, sports, and entertainment industry) & 0.623 & 0.582 & 0.507 & 0.497 & 0.498 & 0.542 \\
\hline \multirow{3}{*}{ Economic driving force } & GDP per capita & 0.334 & 0.382 & 0.374 & 0.317 & 0.406 & 0.363 \\
\hline & Tertiary sector GDP & 0.808 & 0.712 & 0.719 & 0.664 & 0.749 & 0.730 \\
\hline & Tertiary sector GDP as a percentage of total GDP & 0.063 & 0.030 & 0.041 & 0.045 & 0.061 & 0.048 \\
\hline
\end{tabular}

Note: data of the selected indicators are from the China Statistical Yearbook.

transportation pushing force $(0.328>)$. The details are provided as follows:

(1) Industrial pulling force: the GeoDetector analysis results showed that the means of $\mathrm{q}$ values for the development of the culture, sports, and tourism industries were $0.756,0.643$, and 0.810 , respectively. Overall, industrial development was the most important factor affecting the synergistic development of CST industries. Specifically, owing to the recent development, the rapid expansion of individual industries is a prerequisite to achieving the results of $1+1>2$ and $1+1+1>3$. Among them, the $q$ value of tourism industrial development was the highest. In terms of the current path for the synergistic development of the CST industries, characteristic streets and towns, scenic parks, and sports events are dominant product forms. For any of the forms, the pulling force of the tourism industry is more prominent than the sports and culture industries [28]. Furthermore, the culture industry helps the above characteristic business forms to remove the restriction of natural resources and reduce their dependence on the environment, thereby enabling integrated products to surge ahead [29].

(2) Resource attraction force: Iin terms of their effects on the synergistic development of the CST industries in descending order, the five indicators are public finance expenditure on business services and others $(0.791>)$; public financial expenditure on culture, sports, and media (0.657>); fixed asset investment in culture, sports, and entertainment industries
(0.623>); fixed asset investment in catering and accommodation industries $(0.525>)$; and fixed asset investment in water conservation, environment, and public facility management industry (0.524). The values of $q$ were all higher than 0.5 , indicating that the resource attraction force is also a critical factor affecting the synergistic development of the CST industries. Resource factors play a decisive role in the development of the CST industries as, to a certain extent, the purpose of the synergistic development is to use stock resources efficiently, innovate resource allocation, and realise the maximum utility of limited resources [30].

(3) Population supporting force: the mean of $q$ values for employment was 0.773 and that for the total population was 0.568 . In contrast, that for the natural rate of growth was only 0.278 . The results indicate that population supporting force has an important impact on the synergistic development of the CST industries, where employment and the total population are even more critical. Generally, the size of the population is the most critical factor for a market, directly determining the conceivable capacity of the potential target market. Furthermore, the expansion of population size could accelerate the accumulation of local human capital, which is a necessary condition for the rapid development of CST industries [31]. The population age structure and employment structure are also determinants of economic growth and industrial transformation, and employment is the soft condition of industrial development [32]. 
(4) Consumer purchasing power: the mean of q values of the number of people aged 15-64 years was 0.591, that of per capita disposable income of residents was 0.378 , and that of per capita consumption expenditure of residents was 0.217 . The results imply that consumer purchasing power has an important impact on the synergistic development of the CST industries; however, the number of people aged 15-64 years is more important. This development caters for the higher-level consumption demands and implies expanding consumption space. Therefore, monotonous consumer demand and the weak consumption power of residents affect the synergistic development process [33].

(5) Economic driving force: the mean of q values for per capita GDP was 0.363 and that for tertiary sector GDP was 0.730 , whereas that for the tertiary sector GDP as a percentage of total GDP was only 0.048 . Although the economic driving force can drive the synergistic development of the CST industries to a certain extent, the effect from the tertiary sector's GDP as a percentage of total GDP was minimal. The synergistic development of CST industries is necessary for improving the quality of economic development. Therefore, the economic development level and economic comprehensive contribution are the major factors affecting the synergistic development [28]. Capital input is conducive to improving local infrastructure. The tertiary sector GDP reflects the development level of the service industry, whereas enhanced living and tourism services are beneficial to the development of the CST industries.

(6) Transportation pushing force: the four indicators with the highest to lowest influence on the synergistic development of the CST industries were total fixed asset investment (transportation, storage, and postal industry) $0.549>$ public finance expenditure (on transportation) $0.484>$ railway mileage $0.157>$ highway mileage 0.120 . The lower values for railway mileage and highway mileage imply that, although the two factors affect the synergistic development of the CST industries, the impact is limited. Transportation infrastructure is a prerequisite for the rapid development of the tourism industry [34]. It had a considerable impact on sports tourism and cultural tourism; however, its effect on the sports culture industry (e.g., sports and arts performances) may not be so prominent.

\section{Discussion and Conclusion}

4.1. Conclusions. The synergistic development of CST industries is crucial to boosting consumer demand for all three industries, improving the quality of the national economy, and promoting cultural innovation. This provincial-level study used data related to the CST industries of provinces in China from 2013 to 2017. With a coupling coordination model, we calculated the development level index, coupling degree, and coupling coordination degree of CST industries. Subsequently, we explored the spatial characteristics of the synergistic development using the global autocorrelation technique and identified the hot spots, sub-hot spots, subcold spots, and cold spots by leveraging the hot and cold spots analysis technique. Finally, GeoDetector was employed to identify the key driving factors affecting the synergistic development of the CST industries. The findings can be summarised as follows:

(1) The synergistic development of China's CST industries was generally stable in a state of a slight imbalance. In terms of the development level of the three industries, the growth of the sports industry was notable, the tourism industry remained stable, whereas the culture industry decreased slightly. In 2013, both the culture and sports industries lagged behind. However, after 2013, only the culture industry was straggling. In general, the synergistic development of the CST industries in China is still in the nascent stage, and accordingly, improving the development level of the three industries further could enhance the synergistic development.

(2) Notable spatial characteristics in the synergistic development of the CST industries were determined. The differences among these industries across provinces in China were substantial. The general spatial characteristics were at a low development level in northeastern and western China, at a stable and average level in central China, and at a high level in eastern China. The global spatial autocorrelation results showed that the synergistic development of the CST industries had a distinctive "proximity dependence" effect reflected by a notable spatial agglomeration feature and a positive spatial autocorrelation trend. Anhui, Shandong, Jiangsu, Zhejiang, Henan, and Guangdong were hot spots for the synergistic development of CST industries. In contrast, Tibet, Qinghai, Ningxia, and Heilongjiang were cold spots.

(3) The GeoDetector results showed that 21 indicators of six driving factors affect the CST industries' synergistic development. The six factors in the descending order of their influence are industrial pulling force $>$ resource attraction force$>$ population supporting force $>$ consumer purchasing power $>$ economic driving force > transportation pushing force. Among the indicators, the qualues for the development of the CST industries, the total population (year-end) 
employment, number of people aged 15-64 years, total fixed asset investment (transportation, storage, and postal industry), public finance expenditure on culture, sports, and media, and business services and others, fixed asset investment (cultural, sports, and entertainment industry), and tertiary sector GDP were higher than 0.5 , whereas that for tertiary sector GDP as a percentage of total GDP was less than 0.1.

4.2. Discussion. The synergistic development of the CST industries would not be possible without the following three prerequisites: (1) the spatial and temporal coupling of production factors of the CST industries; (2) the business formats generated through integration that can cater to a high level of demand; and (3) common interests and market convergence points for CST industries. The synergistic development of the CST industries offers both explicit and implicit benefits. Explicit benefits include diversifying the tourism product system, expanding tourism consumption space, and promoting the transformation of the tourism industry. The implicit benefits comprise enhanced supply quality of CST industries and optimised supply structure. Culture provides content products and creative thinking for tourism, whereas tourism offers the channel to communicate culture and convert it into saleable goods. Culture brings spiritual connotations and functions as a communication platform for sports, whereas sport builds a consumption market and offers themes and elements for culture. Sports provide content resources and a customer base for tourism, whereas tourism supports sports and utilises sports resources.

Based on the trends and spatiotemporal patterns of the synergistic development of China's CST industries, we propose the following:

(1) Accelerating the development of the cultural, entertainment, and recreational service industry: due to existing structural defects in the investment, ownership, technology, and scale, the development of the cultural, entertainment, and recreational service industry was restricted, leaving it in a state of imbalance for a long time and lagging behind the sports and tourism industries [25]. This would highlight the roles of culture by providing sports with spiritual content, style characteristics, and a communication platform as well as the role of sport in creating consumption demands, endowments, and content for culture. Furthermore, it would emphasise culture's capacity to offer content, ideas, cultural resources, and strong competitiveness to tourism, as well as the latter's contributions to culture as media of information and a path for influencing consumption demands.

(2) Strengthening regional linkage: given the strong spatial dependence of the three industries, a variety of infrastructures could be leveraged to form geographic clusters to maximise the efficacy of limited resources. The measures could be classified as adjacent region and cross-region linkage. This linkage, as suggested, requires leveraging complementary advantages of the CST industries among adjacent regions to promote large-scale development and capture the spillover effects. For example, Anhui Province has successfully turned into a hot spot in the process of building a city cluster in the Yangtze River Delta. The goal of cross-regional linkage is to narrow the gap between well-developed and lessdeveloped regions, ultimately building and improving a synchronised development mechanism across the eastern and western regions.

(3) Devising a holistic plan that accounts for resource allocation and demographic features: industrial upgrading, synergistic development, and optimisation of resource allocation complement each other. The synergistic development of CST industries should be approached from the perspective of resource allocation to expand understanding of the definition, pattern, driving forces, and mechanisms of the synergistic development across industries. Demographic features are essential for an industry, including its sustainable development and industrial structure. Factoring in demographic features into plans will better maintain the sustainable development of the CST industries in China. Previous studies have proposed that the integration of the CST industries is driven by multiple factors to break down industry barriers and experience the dynamic development process of new business forms after the multidimensional integration of technology, business, and market [5]. Hence, the industrial pulling force and resource attraction force corresponding to technology, business, and market should be the top priorities in promoting the synergistic development of the cultural, sports, and tourism industry.

(4) Launching distinctive and high-quality products by merging CST factors to meet the growing needs for "a better life": differentiated cultural experiences, healthy and high-quality lifestyles, and quality services are all conducive to improving public consumption. By establishing a fusion model with sports and cultural resources as the centre and tourism service as the carrier [6], the integration of culture can increase the essence of sports and tourism, whereas sports and tourism can better promote the development of culture [9]. For example, meeting consumers' needs in pursuit of events, tourism, and emotional experiences in sports and fitness activities could provide them with an unforgettable experience of physical and mental pleasure.

\section{Data Availability}

The raw data supporting the conclusions of this article can be made available by the authors to qualified researchers. 


\section{Conflicts of Interest}

The authors declare no conflict of interest.

\section{Authors' Contributions}

Ji Li and Yifan Zuo conceptualised the study; Ji Li, Jiabao Cui, and Qihang Qiu designed methodology; Xuan Liu provided software; Ji Li and Jiangtao Xia validated the data; Jiabao Cui investigated the study; Ji Li and Yifan Zuo curated the data; Ji Li, Jiangtao Xia, and Yifan Zuo wrote the original manuscript and prepared the draft; Ji Li, Yifan Zuo, Qihang Qiu, and Hongfa Zeng wrote, reviewed, and edited the manuscript; Ji Li visualised the data; and all authors have read and agreed to the published version of the manuscript.

\section{Acknowledgments}

This work was supported by the National Social Science Fund of China (grant no. 19BTY066).

\section{References}

[1] F. Lemoine, S. Poncet, and D. Ünal, "Spatial rebalancing and industrial convergence in China," China Economic Review, vol. 34, pp. 39-63, 2015.

[2] L. Pingkuo, P. Huan, and W. Zhiwei, "Orderly-synergistic development of power generation industry: a China's case study based on evolutionary game model," Energy, vol. 211, Article ID 118632, 2020.

[3] P. Qiu, Z. Zhou, and D.-J. Kim, "A new path of sustainable development in traditional agricultural areas from the perspective of open innovation-A coupling and coordination study on the agricultural industry and the tourism industry," Journal of Open Innovation: Technology, Market, and Complexity, vol. 7, no. 1, p. 16, 2021.

[4] Y. Gong, X.-Q. Yang, C.-Y. Ran, V. Shi, and Y.-F. Zhou, "Evaluation of the sustainable coupling coordination of the logistics industry and the manufacturing industry in the Yangtze River economic Belt," Sustainability, vol. 13, no. 9, p. 5167, 2021.

[5] Y. Xiaoyu, "Era value and promotion strategy of integrated development of sports, travel, culture, business and agriculture," Sports Culture Guide, no. 4, pp. 79-84, 2020.

[6] F. Liang, "Promoting the integrated development and path optimization of sports industry and tourism industry," International Journal of Frontiers in Sociology, vol. 2, pp. 114$122,2020$.

[7] J. Fugao and C. Li, "All-for-One sports tourism: connotation characteristics, spatial structures and development patterns," Journal of Shanghai University of Sport, vol. 44, pp. 12-23, 2020.

[8] Y. Zuo, H. Chen, J. Pan, Y. Si, R. Law, and M. Zhang, "Spatial distribution pattern and influencing factors of sports tourism resources in China," ISPRS International Journal of Geo-Information, vol. 10, no. 7, p. 428, 2021.

[9] L. Zhang, "Design of a sports culture data fusion system based on a data mining algorithm," Personal and Ubiquitous Computing, vol. 24, no. 1, pp. 75-86, 2020.

[10] Z. Deli, Y. Weizeng, L. Chenggang, and Z. Feng, "Resource endowment and cultural identity: sustainable development of regional sports culture industry--consideration on the development of Anhui sports industry," Journal of Sports Science, vol. 40, pp. 74-79, 2019.

[11] R. Bachleitner and A. H. Zins, "Cultural tourism in rural communities," Journal of Business Research, vol. 44, no. 3, pp. 199-209, 1999.

[12] K. Rudokas, M. Landauskas, I. Gražulevičiūtè-Vilneiškè, and O. Viliūniene, "Valuing the socio-economic benefits of built heritage: local context and mathematical modeling," Journal of Cultural Heritage, vol. 39, pp. 229-237, 2019.

[13] N. P. N. E. Lestari, M. K. S. Budhi, and I. M. Suidarma, "The role of subak as culture capital to develop community based tourism village (case study in Pinge Village, Bali Province, Indonesia)," Scientific Papers Series-Management, Economic Engineering in Agriculture and Rural Development, vol. 19, pp. 357-367, 2019.

[14] Z. Gao, M. Li, F. Gao, X. Wang, and A. Naddeo, "Fuzzy comprehensive evaluation on body parts' weight coefficients towards sitting comfort based on AHP to limit entropy method," Mathematical Problems in Engineering, vol. 2019, Article ID 3826468, 11 pages, 2019.

[15] Y. Li, Y. Li, Y. Zhou, Y. Shi, and X. Zhu, "Investigation of a coupling model of coordination between urbanization and the environment," Journal of Environmental Management, vol. 98, pp. 127-133, 2012.

[16] Z. Tang, "An integrated approach to evaluating the coupling coordination between tourism and the environment," Tourism Management, vol. 46, pp. 11-19, 2015.

[17] L. Xing, M. Xue, and M. Hu, "Dynamic simulation and assessment of the coupling coordination degree of the economyresource-environment system: case of Wuhan City in China," Journal of Environmental Management, vol. 230, pp. 474-487, 2019.

[18] L. Li, Q. Yang, S. Changcheng, X. Xie, Z. Fengtai, and A. C. Teodoro, "Coupling coordinated evolution and forecast of tourism-urbanization-ecological environment: the case study of chongqing, China," Mathematical Problems in Engineering, vol. 2021, Article ID 7271637, 15 pages, 2021.

[19] Y. Zuo, L. Zou, M. Zhang et al., "The temporal and spatial evolution of marathons in China from 2010 to 2018," International Journal of Environmental Research and Public Health, vol. 16, no. 24, p. 5046, 2019.

[20] X. Zhao, G. Yu, and A. Neagu, "Data-driven spatial econometric analysis model for regional tourism development," Mathematical Problems in Engineering, vol. 2021, Article ID 6631833, 7 pages, 2021.

[21] Z. Ren, Y. Zuo, Y. Ma et al., "The natural environmental factors influencing the spatial distribution of marathon event: a case study from China," International Journal of Environmental Research and Public Health, vol. 17, no. 7, p. 2238, 2020.

[22] W. Jinfeng and X. G. Chengdong, "Principle and prospective," Acta Geographica Sinica, vol. 72, pp. 116-134, 2017.

[23] M. Treimer, B. Allert, K. Dylla, and G. Müller, "Uncertainty quantification applied to the mode coupling phenomenon," Journal of Sound and Vibration, vol. 388, pp. 171-187, 2017.

[24] Y. Wang, Y. Wang, and M.-X. Li, "Regional characteristics of sports industry profitability: evidence from China's province level data," Physica A: Statistical Mechanics and Its Applications, vol. 525, pp. 946-955, 2019.

[25] H. Ju, "Research on the efficiency measurement of Chinese cultural manufacturing industry based on DEA method," International Journal of Frontiers in Sociology, vol. 1, pp. 32-42, 2019. 
[26] Z. Tang, J. Shang, C. Shi, Z. Liu, and K. Bi, "Decoupling indicators of $\mathrm{CO}_{2}$ emissions from the tourism industry in China: 1990-2012," Ecological Indicators, vol. 46, pp. 390-397, 2014.

[27] R. Bo, "Research on the coupling and coordination relationship between sports industry and cultural industry in China," Journal of Yancheng Teachers University (Humanities \& Social Sciences Edition), vol. 40, pp. 95-106, 2020.

[28] L. Weng, B.-J. He, L. Liu, C. Li, and X. Zhang, "Sustainability assessment of cultural heritage tourism: case study of pingyao ancient city in China," Sustainability, vol. 11, no. 5, p. 1392, 2019.

[29] H. Chen, Y. Zuo, R. Law, and M. Zhang, "Improving the tourist's perception of the tourist destinations image: an analysis of Chinese Kung fu film and television," Sustainability, vol. 13, no. 7, p. 3875, 2021.

[30] R. S. Turner and M. S. Rosentraub, "Tourism, sports and the centrality of cities," Journal of Urban Affairs, vol. 24, no. 5, pp. 487-492, 2002.

[31] C. I. Jones and P. M. Romer, "The new Kaldor facts: ideas, institutions, population, and human capital," American Economic Journal: Macroeconomics, vol. 2, no. 1, pp. 224-245, 2010.

[32] F. Cai and M. Wang, "Growth and structural changes in employment in transition China," Journal of Comparative Economics, vol. 38, no. 1, pp. 71-81, 2010.

[33] Q. Wang and X. Yang, "Urbanization impact on residential energy consumption in China: the roles of income, urbanization level, and urban density," Environmental Science and Pollution Research, vol. 26, no. 4, pp. 3542-3555, 2019.

[34] G. V. Herman, J. A. Wendt, R. Dumbravă, and M. Gozner, "The role and importance of promotion centers in creating the image of tourist destination: Romania," Geographia Polonica, vol. 92, no. 4, pp. 443-454, 2019. 